\title{
Safety and toxin-producing ability of bacillary microbiota of Ukrainian plant raw materials and products.
}

\author{
Pylypenko LN ${ }^{1 *}$, Lopotan IV ${ }^{1}$, Yamborko G V², Ilyeva ES ${ }^{1}$, Pelykh VG \\ ${ }^{1}$ Department of Biochemistry, Microbiology and Nutrition Physiology, Odessa National Academy of Food Technologies \\ ${ }^{2}$ Biotechnological Research and Training Centre, Odessa I. I. Mechnikov National University, Odessa
}

Keywords: Bacillary microbiota, Plant products, Facultative anaerobic, Phenotypic characteristic, PCR

Accepted on April 13, 2018

\section{Short Communication}

The distinction and identification of bacilli as the representatives of the plant raw material epiphytic microbiota is a necessary step for forecasting and ensuring the safety of plant products. It allows promptly adjusting their technological processing, which ensures the accordance of food products to the international standards. Standardized methods of diagnosing the safety of food and raw materials are classical methods of food microbiology, based on the phenotypic characteristics of microorganisms, which are time-taking and not always able to diagnose the microbial toxigenic properties [1]. The analytical information about the inaccuracy of the indication of bacillary food poisoning agents, the need for preventive analysis of risks associated with aerobic and facultative anaerobic spore forming microorganisms of Bacillales order results in the urgency of their detection by accelerated modern methods [2].

The purpose of the work was to characterize the composition of the microbiota of plant raw materials and products of their processing and to develop accelerated molecular biological diagnostics of bacillary food poisoning agents and product spoilage (contaminants of the genuses Bacillus, Paenibacillus) by the genetic determinants of their toxicity. Characteristics of microorganisms were studied with standardized classical methods by phenotypic properties and molecular biological methods [3].

For the first time the group composition of microbial contaminants of 217 samples of different plant raw material species and products of their processing were investigated according to the mesophilic aerobic and facultative anaerobic microorganisms (MAFAnM), mold fungi and yeasts quantity. The dominance of MAFAnM by 2-3 orders among the groups of microorganisms was established [4]. The research of the group composition of microbial contaminants of the most widespread plant raw material species shows that MAFAnM varies from $4.6 \times 10^{4} \mathrm{CFU} / \mathrm{g}$ on tomatoes surface to $8.4 \times 10^{6}$ on carrots surface, while the quantity of mold fungi varies from $2.7 \times 10^{2}$ $\mathrm{CFU} / \mathrm{g}$ on pepper to $5.2 \times 10^{4}$ on carrots, the quantity of yeasts from $0.9 \times 10^{2}$ on vegetable marrows to $1.7 \times 10^{5} \mathrm{CFU} / \mathrm{g}$ with carrots. The biodiversity of microbiota vegetating on tested plant raw material was mainly formed by the spore-forming bacteria species that are the potential agents contaminating of the foodstuff $[5,6]$.
By phenotypic characteristics of contaminants from 217 food samples, which were studied by standardized classical methods; it was found that they belong to 9 morphotypes. Among the bacillary contaminants of the samples, the Bacillus subtilis and Bacillus licheniformis group is the most numerous one (20 to $37 \%$ of total bacilli count), Bacillus megaterium was detected in amount of 6 to $21 \%$, Bacillus pumilus in amount of 4 to $13 \%$, Bacillus circulans in 2 to $7 \%$, gas-forming Paenibacillus polymyxa and Paenibacillus macerans (the causative agents of bombarding spoilage) are in amount of 3 to $14 \%$ and 2 to $9 \%$ respectively, while the microorganisms of the Bacillus cereus group (in particular Bacillus cereus and Bacillus thuringiensis) are in $10-31 \%$ and $4-13 \%$ respectively. Analysis of potential pathogens of food intoxications, toxicoinfections and food spoilages occurring among the biodiversity of microbiota vegetating on the investigated samples, which consist mainly of bacteria with predominance of spore-forming species, was shown to be complicated and long time-taking $[7,8]$.

The priority technique for preliminary preparing food samples has been developed by us and Polymerase Chain Reaction (PCR) parameters with selected group and species specific primers have been optimized. PCR was carried out with specific primers to detect toxin codes in various kinds of bacilli genes: $n h e, h b l$, $c y t K$. Molecular genetic diagnosis showed the specificity of the contaminants in Ukraine, the presence of the nhe gene was detected in $100 \%$ of Bacillus cereus strains, $h b l$ in about $60 \%$ and $c y t K$ in about $40 \%$ of the strains studied. This provides a way to diagnose regulated bacillary contaminants in the test samples that affect the safety of products by Bacillus cereus strains. It should be noted that the presence of the toxicity gene was found in a typical saprophytic strain. Studies of food raw materials and products have confirmed the need to improve microbiological control of product safety by introducing accelerated specific diagnostics of contaminants by molecular genetic methods.

\section{Conclusion}

As a result of the research, a microbiota composition of plant raw materials and products of their processing was studied; accelerated molecular biological diagnosis of bacillary food poisoning agents and product spoilage was elaborated. A technique for preliminary preparation of food samples was developed and the Polymerase Chain Reaction parameters were optimized with selected group and species-specific primers for diagnosing regulated bacillary contaminants that affect 
the products' safety in the tested samples. Such diagnostics will allow producing new competitive products of guaranteed quality and microbiological safety.

\section{Reference}

1. World Health Organization (WHO). The International Food Safety Authorities Network (INFOSAN). http://www. who. int./foodsafety/fs_management/infosan/en/ 2008 Oct;1(1):1-3.

2. Draft commission regulation on microbiological criteria for foodstuffs. (Document SANCO/4198/2001 (2005), Commission of the European communities, Brussels; pp:34.

3. Dzhej M, Lessner M, Golden DA. Modern Breeding Microbiology, BINOM. Laboratory knowledge, 2014;886.

4. Pylypenko L, Verhivker G, Pylypenko V. Preservation of food: microbiology, energetics, control. Microbiology, Odessa, 2015:232.

5. Blackburn Clive de W. Food spoilage microorganisms, CRC Press.Woodhead Publishing Ltd, Cambridge, England; 2006:736.

6. Pylypenko V, Paulina Ya B, Pylypenko L, et al. Composition of microbial contaminants of vegetable raw materials.
Microbiology and Biotechnology. 2015;3 (31):83-94.

7. Pylypenko L, Ivanitsya V, Pylypenko I, et al. Method of preliminary preparation of samples for the identification of microorganisms, BULL;2017:12.

8. Pylypenko V, Pylypenko L, Ilyeva OS, et al. Bacillus cereus: Characteristic biological action, peculiarities of determination in food products / Food Science and Technology. 2017;11(2): 61-7.

\section{*Correspondence to:}

Pylypenko LN

Department of Biochemistry, Microbiology and Nutrition Physiology

Odessa National Academy of Food Technologies Ukraine

Email: 1.n.pylypenko@ukr.net 